\title{
Drug package as a cause of gastric outlet obstruction
}

A 42-year-old man - a former drug addict with human immunodeficiency virus (HIV) infection and hepatitis $C$ virus hepatic cirrhosis Child-Pugh B - reported voluntary intake of a packet of hashish for concealment 3 years earlier while he was detained in prison. He was asymptomatic until 4 months before presentation, when he began complaining of halitosis, belching, bloating, nausea and food vomiting which relieved the symptoms. These episodes were sporadic, but with increasing frequency in recent weeks. Four days before admission, vomiting became more intense and the patient complained of a single episode of hematemesis. At hospital admission he was hemodynamically stable, without ascites or peritoneal signs. Upper gastrointestinal endoscopy revealed small esophageal varices and severe portal hypertensive gastropathy, assumed as the cause of bleeding. It detected the presence of a gastric foreign body of about $10 \mathrm{~cm}$ with a hard consistency ( $\bullet$ Fig. 1). Upper gastrointestinal endoscopy was repeated under sedation on the following day, during which the foreign body was removed without complications ( Fig.2). During hospitalization, the patient remained hemodynamically stable, without blood loss. He was asymptomatic when discharged.

Endoscopic removal of drug packages is not recommended except when only one packet fails to pass the pylorus. Hashish overdose causes depression of consciousness that isn't generally life threatening, unlike overdose of heroin or cocaine [1 3]. In this case, we assumed that the package was causing obstructive symptoms, that its spontaneous progression would be unlikely, that the surgical risk would be high, and that a possible overdose would not threaten the patient's life, and we therefore decided to perform its endoscopic removal.

\section{Endoscopy_UCTN_Code_TTT_1AO_2AL}

\section{Competing interests: None}

\section{R. Küttner Magalhães, T. Moreira, R. Pimentel, C. Caetano, I. Pedroto}

Department of Gastroenterology, Hospital Santo António, Porto, Portugal

\section{References}

1 American Society for Gastrointestinal Endoscopy. Management of ingested foreign bodies and food impactions. Gastrointest Endos 2011; 73: 1085-1091

2 Traub S, Hoffman RS, Nelson LS. Body packing - the internal concealment of illicit drugs. $\mathrm{N}$ Engl J Med 2003; 349; 26: 2519-2526

3 Cotton P, Williams C. Therapeutic upper endoscopy. In: Practical gastrointestinal endoscopy: the fundamentals. 6th edn. Wiley-Blackwell; 2008: 61 -86

\section{Bibliography}

DOI http://dx.doi.org/

10.1055/s-0031-1291696

Endoscopy 2012; 44: E421

(c) Georg Thieme Verlag KG

Stuttgart · New York

ISSN 0013-726X

\section{Corresponding author}

\section{R. Küttner Magalhães, MD}

Department of Gastroenterology

Hospital Santo António

59 Rua Dr Eduardo Santos Silva

4200-282 Porto

Portugal

Fax: +351-22-3320318

rkuttner@gmail.com
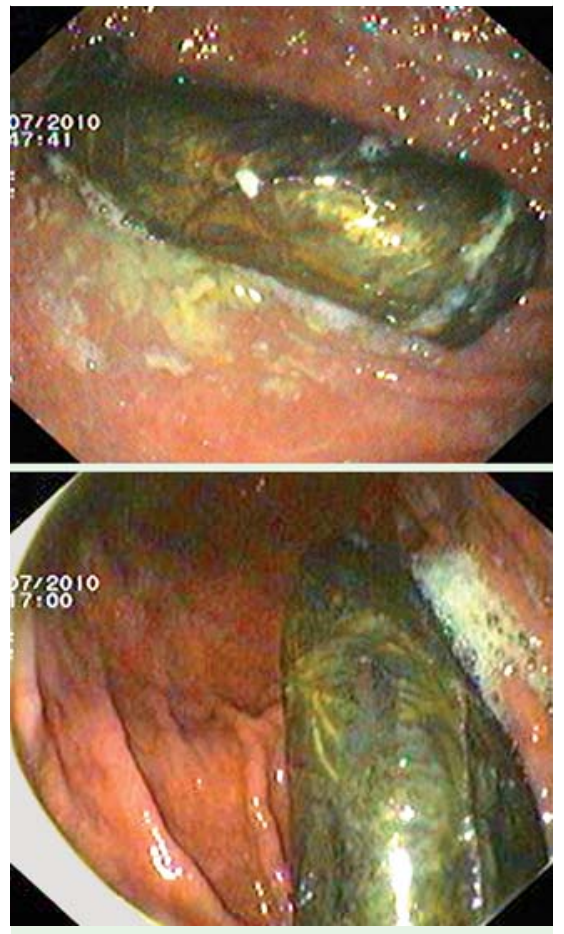

Fig. 1 Endoscopic images of the foreign body.

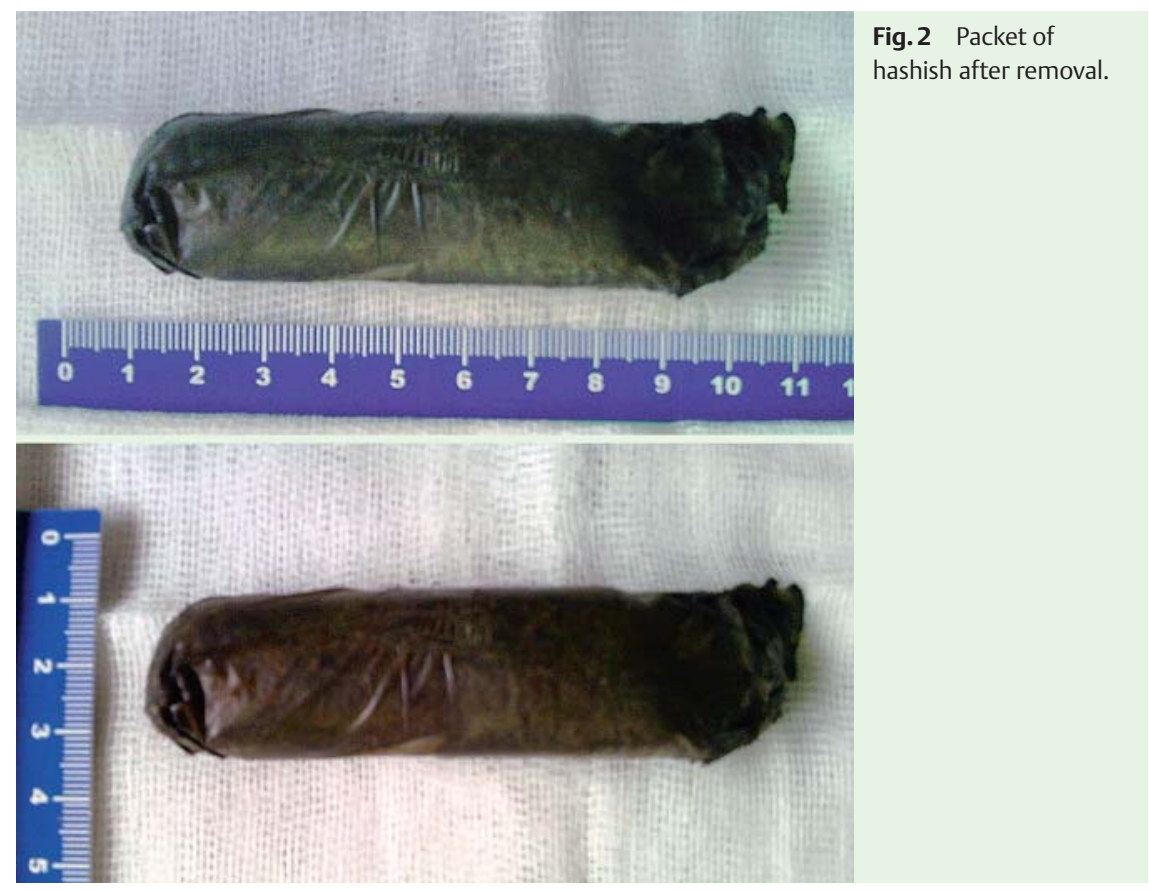

